\title{
Relationship between Foot-Care Self-Efficacy Beliefs and Self Care Behaviors in Diabetic Patients in Iran (2011)
}

\section{Maryam Shabani Hamedan ${ }^{1 *}$, Marzieh Shabani Hamedan² and Zeinabe sadegh Torki}

${ }^{1}$ Department of Medical-Surgical in Nursing, College of Nursing and Midwifery/paramedical science, Qazvin, University of Medical Sciences, Iran ${ }^{2}$ Department of Public health, College of health science, Iran University of Medical Sciences, Tehran

${ }^{3}$ Department of Medical-Surgical in Nursing, College of Nursing and Midwifery, Iran University of Medical Sciences, Tehran

\begin{abstract}
Aims and objectives: Diabetes mellitus and its chronic complications have put a huge burden on the health care system. The diabetic patients with foot problems compared with other diabetic patients create more critical problems for the health care system. This study was done for the purpose of studying the relation between foot-care self-efficacy beliefs and self care behavior.

Method: This study was a descriptive-correlation type and was done as sectional which sampling lasted about one month. 70 diabetic patients participated in this study with a convenience sampling method. Data collection was done by clinical-demographic questionnaire and foot care self efficacy beliefs and self care behavior scales. Data analysis was done by spss 15 .

Result: Pearson correlation was performed and showed a negative correlation between FCCS scores and preventive behavior scores $(r=0.44, p \leq 0.001)$ and virtually no correlation at all between FCCS scores and potentially damaging behaviors $(r=0.15, p=0.19)$. Also there was a relation between age and preventive behavior $(F=6.42$, $\mathrm{P}=0.03$ ) and duration of diabetes and preventive behavior $(F=9.65, P \leq 0.001)$. Furthermore there was a relation between education level and potentially damaging behaviors $(F=2.65, P=0.04)$.

Discussion and conclusion: Regarding these results, foot care self-efficacy beliefs and self care behaviors have a weak relationship so self-efficacy belief is directly related to self care behavior. Also patients with diabetes, especially older diabetic patients with low education level should be advised to perform self care behavior and assessed for self efficacy beliefs because they have many problems in self care.
\end{abstract}

Keywords: Diabetes; Foot care; Self care; Self-efficacy

\section{Introduction}

Diabetes mellitus and its chronic complications have put a huge burden on health care system. According to the report of the World Hygiene Organization, at least 170 million people suffer from diabetes in the world. And this figure will be doubled in 2030 [1]. In Iran, one among every five people above 30 years of age suffers from diabetes. In a world that is faced with epidemic of diabetes type two, foot ulcer leading to lower limb amputation has been turned to a common, important, and universal problem $[2,3]$. According to the investigations, out of five diabetic patients who referred to the hospital, one patient suffered from foot problem. It is estimated that 4 to 10 percent of diabetic patients will get foot ulcer. The diabetic patients with the foot problems compared with other diabetic patients produce more critical conditions for the health care system [4].

In Australia more than 25 percent of lower limb amputations have been reported that 80 percent of which had been caused by a foot ulcer. The last investigations have shown that the reasons of foot ulcer are the unchangeable multi agents with damaging peripheral nerves $[5,6]$. For helping the diabetic people and the persons who suffer from peripheral neuropathy, we should pay attention to all biochemical, biomechanical, psychological, behavioral, and environmental factors. A lot of investigations have been done in the case of special care of the foot being able to prevent foot ulcers [7]. The testimonies show that the diabetic patients often do not apply the offered behavioral strategies in the educational interventions. Previous studies have showed that only the 20 percent of diabetic foot ulcer participants examined their feet carefully and also 23 to 25 percent never did this. Patient education about self care and self efficacy play an important role in foot damage prevention [8,9]. According to the Orem's theory, people perform some activities to have a good feeling so that they take care of their health and life. Total self-care practices are found on deliberate practice [10].

On the other hand, self-efficacy describes the interaction between behavioral, personal, and environmental factors in health and chronic disease and it is the patients' confidence in their ability to perform health behaviors which influences behaviors they will engage in $[11,12]$. Indeed, self-efficacy represents the individual's belief as to how successfully people perform a behavior needed to produce certain results [12]. It has been estimated that the risk of foot ulcer will decrease with foot care. Also the patient beliefs and the medical cares, formal and informal education, and many other factors are effective in it [13]. A low number of studies have been conducted in the case of patient's beliefs about self care and the foot care behaviors in Iran [8]. Moreover, most of the studies have considered the diabetic patient self care from a general point of view and since there are few studies in this field in Iran, the need for conducting such studies is appreciable.

*Corresponding author: Maryam Shabani Hamedan, Department of MedicalSurgical in Nursing, College of Nursing and Midwifery/paramedical science, Qazvin University of Medical Sciences, Iran, E-mail: maryamshabanyi@yahoo.com

Received August 22, 2012; Accepted October 22, 2012; Published October 28 2012

Citation: Hamedan MS, Hamedan MS, Torki ZS (2012) Relationship between Foot-Care Self-Efficacy Beliefs and Self Care Behaviors in Diabetic Patients in Iran (2011). J Diabetes Metab 3: 220. doi:10.4172/2155-6156.1000220

Copyright: @ 2012 Hamedan MS, et al. This is an open-access article distributed under the terms of the Creative Commons Attribution License, which permits unrestricted use, distribution, and reproduction in any medium, provided the original author and source are credited. 


\section{Materials and Method}

\section{Study design and measurement tool}

This study was a descriptive-correlation, cross sectional type that was done for the purpose of considering the relation between the footcare self-efficacy beliefs and self care behavior. Sampling lasted for one month. 70 diabetic patients participated in this study in a convenience sampling method. Researchers were from the Human Ethics Committee medical science of Tehran University. Environmental study was carried on at the diabetic patients association where patients were referred from all parts of Tehran. For considering the clinical and demographic variables, the questionnaire of personal information with questions about age, sex, education level, diabetes duration, and the diabetes type variables was distributed among patients. These were considered as an interferer variable and were used for describing the samples and its relation with the behaviors of foot care and self efficacy belief. In this study, foot care behaviors are the behaviors and activities that protect patient's life and heath and prevent foot injuries. For evaluating this variable, the Sloan questionnaire [14] was used. This questionnaire included 17 questions which were divided into two behavioral subscales in which 9 questions were about preventive behaviors and 8 questions were about foot potential harmful behaviors. This questionnaire divided the questions into two parts according to six choice questions of Likert scale (two times a day, daily, every other day, two times a week, one time a week and never) and four choice divisions are scored from 0 to 1 of Likert scale (always, most of the time, often and ever). The questionnaire is applicable as self adjustable and interview and its completion lasted for 10 minutes. The second questionnaire was the Foot Care Confidence Scale (FCCS) (vileikyte et al.) questionnaire [7]. This questionnaire included 12 sentences due to the difference in scales, which were related to the people's confidence about their foot. This questionnaire was based on the 5 choice Likert scale and was scored from 1 to 5 (STRONGLY NOT CONFIDENT $=1$, MODERATELY NOT CONFIDENT $=2, \quad$ CONFIDENT $=3$, MODERATELY CONFIDENT $=4$, STRONGLY CONFIDENT $=6$ ). The minimum score is 12 and the maximum score 60 . Academic validity of the tools was determined through the content validity. The sampling in this project included diabetic patients, above 18 who had the ability to fill the questionnaire or do the interview and had the tendency to participate in the project. The patients who suffered from psychological disease or functional inability (muscular-skeletal) were omitted from the study. The project samples were also selected with convenience sampling method.

After explaining about the research objects and emphasizing on the information confidentiality and obtaining agreement from the patients, the required information was collected from the samples. The data was analyzed by the SPSS software, version 15 . For achieving the research object, the descriptive-inferential statistics were used (ANOVA test and independent t-test and Pearson correlation).

\section{Results}

Analysis of the data shows that the diabetic patients' average age was $(58.41 \pm 10.17)$, the minimum age was 18 and the maximum age was 87 . Most of the samples were women (64.3\%). The average length of the diabetes disease was $11.8 \pm 9.3$. The minimum duration of diabetes disease was 21-30 years (4.3\%) and the maximum duration of diabetes disease was 11-20 years $(72.2 \%)$. Most of the patients had junior high school and high school education (54.6\%) and the minimum of them had university education (9.1\%). Most of the patients suffered from diabetes type II $(70 \%)$ and the rest suffered from the diabetes types I. Table 1 of independent $t$-test shows that there is no significant difference between the sex and the foot harmful potential behaviors $(\mathrm{p}=0.06, \mathrm{t}=0.7)$ and the preventive behaviors $(\mathrm{p}=0.52, \mathrm{t}=0.64)$. One way ANOVA test showed that there is a relation between the preventive behaviors in foot care and diabetes duration $(\mathrm{p} \leq 0.001, \mathrm{f}=9.65)$ and the Scheffe test showed that there is no relation between age group and the foot harmful potential behaviors with the duration of diabetes $(p=0.37$, $\mathrm{F}=1.09$ ). There was no relation between the diabetes test type with the foot care preventive behaviors $(\mathrm{p}=0.92, \mathrm{t}=0.709)$ and between foot harmful potential behaviors and diabetes types $(\mathrm{p}=0.88, \mathrm{t}=2.66)$. There was a significant relation between foot care preventive behaviors with patient's age $(\mathrm{p}=0.03, \mathrm{~F}=6.42)$ and there was no significant relation between age and foot harmful potential behaviors $(\mathrm{p}=0.28, \mathrm{~F}=1.29)$. There was a significant relation between education level with foot

\begin{tabular}{|c|c|c|c|c|c|c|}
\hline \multirow[b]{2}{*}{$\begin{array}{l}\text { Age } \\
\text { Mean (SD) } \\
58 / 41 \pm 10 / 17\end{array}$} & & \multicolumn{2}{|c|}{$\begin{array}{l}\text { Mean score of } \\
\text { preventive behaviors } \\
0 / 86 \pm 0 / 31\end{array}$} & \multicolumn{2}{|c|}{$\begin{array}{l}\text { Mean score of } \\
\text { preventive behaviors } \\
0 / 64 \pm 0 / 12\end{array}$} & \multirow[b]{2}{*}{ Statistical test } \\
\hline & & $F=6 / 42$ & $\mathrm{P}=0 / 03^{*}$ & $F=1 / 29$ & $P=0 / 28$ & \\
\hline Sex & n (\%) & \multirow{3}{*}{$t=0 / 64$} & \multirow{3}{*}{$P=0 / 52$} & \multirow{3}{*}{$\mathrm{t}=0 / 7$} & \multirow{3}{*}{$P=0 / 06$} & \multirow{3}{*}{ Statistical test } \\
\hline Male & $25(35 / 7)$ & & & & & \\
\hline Female & $45(64 / 3)$ & & & & & \\
\hline $\begin{array}{l}\text { duration of diabete } \\
\text { Mean (SD) } \\
9 / 3 \pm 11 / 8\end{array}$ & & \multirow[t]{2}{*}{$F=9 / 65$} & \multirow[t]{2}{*}{$P \leq 0 / 001^{*}$} & \multirow[t]{2}{*}{$F=1 / 09$} & \multirow[t]{2}{*}{$P=0 / 37$} & \multirow[t]{2}{*}{ Statistical test } \\
\hline Education level & n (\%) & & & & & \\
\hline Uneducated & $13(19 / 7)$ & \multirow{5}{*}{$F=1 / 27$} & \multirow{5}{*}{$P=0 / 29$} & \multirow{5}{*}{$F=2 / 65$} & \multirow{5}{*}{$P=0 / 04^{*}$} & \multirow{5}{*}{ Statistical test } \\
\hline 1-5 grade & $11(16 / 7)$ & & & & & \\
\hline Middle & $18(27 / 3)$ & & & & & \\
\hline high-school level & $18(27 / 3)$ & & & & & \\
\hline College & $6(9 / 1)$ & & & & & \\
\hline Type of diabetes & n (\%) & \multirow{3}{*}{$\mathrm{t}=0 / 70$} & \multirow{3}{*}{$P=0 / 92$} & \multirow{3}{*}{$t=2 / 66$} & \multirow{3}{*}{$P=0 / 88$} & \multirow{3}{*}{ Statistical test } \\
\hline 1 & 21(30) & & & & & \\
\hline 2 & $49(70)$ & & & & & \\
\hline
\end{tabular}

*significant relationship

Table 1: Demographic characteristics of patients. 
Citation: Hamedan MS, Hamedan MS, Torki ZS (2012) Relationship between Foot-Care Self-Efficacy Beliefs and Self Care Behaviors in Diabetic Patients in Iran (2011). J Diabetes Metab 3: 220. doi:10.4172/2155-6156.1000220

Page 3 of 5

harmful potential behaviors $(\mathrm{p}=0.04, \mathrm{~F}=2.65)$ and there was no relation among preventive behaviors $(\mathrm{p}=0.29, \mathrm{~F}=1.27)$. Pearson correlation was performed and showed a positive correlation between FCCS scores and preventative behavior scores $(\mathrm{r}=0.44, \mathrm{p} \leq 0.001)$ and virtually no correlation at all between FCCS scores and potentially damaging behaviors $(\mathrm{r}=0.15, \mathrm{p}=0.19)$ (Table 2). About significant statistic tests 3 graphs are plotted to show comparison between mean scores of preventive behaviors, potentially damaging behaviors and Foot Care Confidence Scale (FCCS) with age (A) (Figure 1), duration of diabetes (B) (Figure 2) and educational levels (C) (Figure 3).

\begin{tabular}{|l|l|}
\hline & $\begin{array}{l}\text { Mean of score foot-care } \\
\text { self-efficacy } \\
\text { beliefs } \\
\mathbf{3 6 / 6 2 \pm} \mathbf{6 / 8 1}\end{array}$ \\
\hline $\begin{array}{l}\text { Mean score of preventive behaviors } \\
\mathbf{0} \mathbf{8 6 \pm 0 / 3 1}\end{array}$ & $\left(\mathrm{r}=0.44, \mathrm{p} \leq 0.001^{*}\right)$ \\
\hline $\begin{array}{l}\text { Mean score of potentially damage behaviors } \\
\mathbf{0} / \mathbf{6 4} \pm \mathbf{0} / \mathbf{1 2}\end{array}$ & $(\mathrm{r}=0.15, \mathrm{p}=0.19)$ \\
\hline
\end{tabular}

*significant relationship

Table 2: Relationship between foot-care self-efficacy beliefs and behavior.

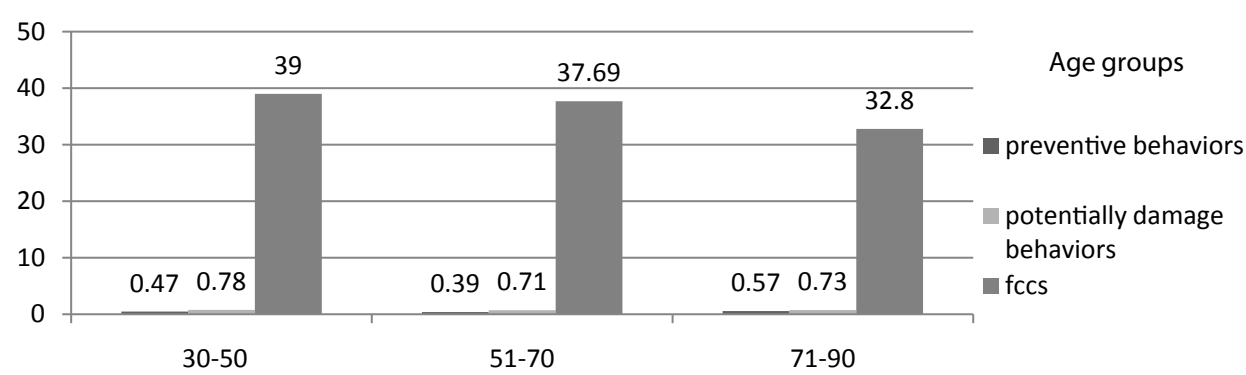

Figure 1: ANOVA showed that in 70-90 group had the highest mean score preventive behaviors (A) ANOVA showed that in 30-50 group had the highest mean score of potentially damage behaviors ANOVA showed that in 30-50 age group had the highest mean score of fccs.

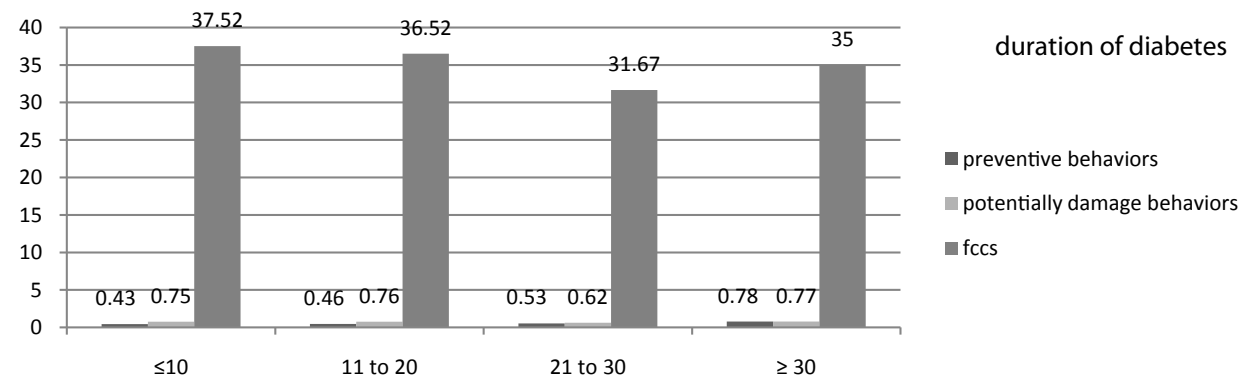

Figure 2: ANOVA showed that duration of diabetes in $\geq 30$ group had the highest mean score preventive behaviors (B) ANOVA showed that duration of diabetes in $\geq 30$ group had the highest mean score of potentially damage behaviors ANOVA showed that duration of diabetes in $\leq 10$ group had the highest mean score of fccs

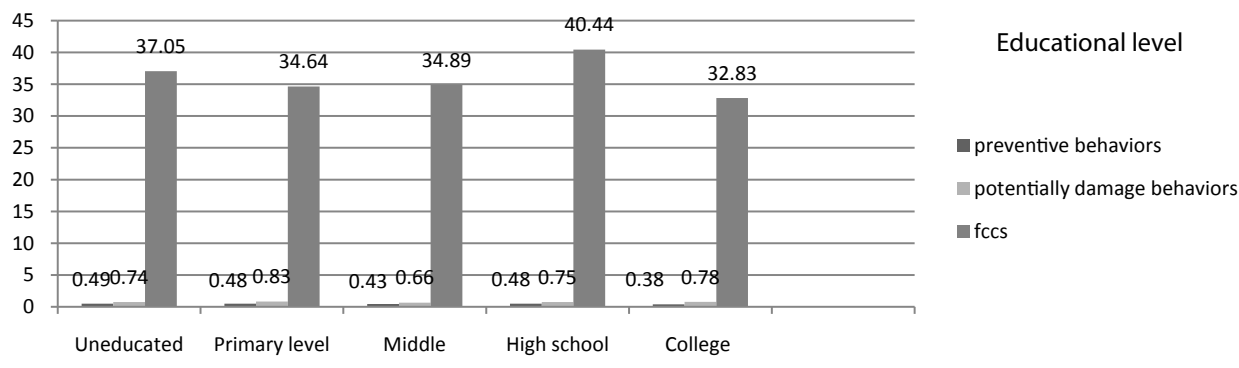

Figure 3: ANOVA showed that the uneducated level had the highest mean score preventive behaviors (C) ANOVA showed that the primary level had the highest mean score potentially damage behaviors ANOVA showed that High school level had the highest mean score of fccs. 


\section{Discussion}

The results of this study showed that there was a relationship between foot-care self-efficacy beliefs and self care behavior. Also there was a significant positive relationship between self efficacy beliefs and preventive behaviors subscale but there was not a significant relationship between self-efficacy beliefs and potentially damaging behaviors. These findings were similar to Byron M Perrin's study [8]. They reported a weak relationship between preventive behaviors and foot-care self-efficacy; also they showed that there wasn't a significant relationship between self-efficacy beliefs and potentially damaging behavior. They cited that if there was a strong relationship between self-efficacy beliefs and behavior it would be expected that those with weaker foot-care self-efficacy beliefs would be more likely to undertake potentially damaging behaviors.

Generally several studies showed that higher self-efficacy is associated with higher self care. Sumalee Chuepan study [15] showed that foot care behaviors and self-efficacy have a significant relationship. They cited "The foot care behaviors are important for patients with diabetes to reduce high-risk of foot ulcer and lower-extremity amputation that impact their quality of life". They demonstrated positive correlation between diabetes self-efficacy and self-care subscales.

Furthermore, Sarkar et al. [16] confirmed it. In present study, there was no significant relationship between self-efficacy belief and potentially damage. In general, a self-efficacy belief has a significant impact on performance and behavior, on the other hand understanding and prediction of behavior in different people is complex. So selfefficacy according to thought and action is different [17]. It is likely that it is difficult to predict the potential behavior with some questions. Also, Behavior change theories and models from the social and behavioral sciences explain the biological, cognitive, behavioral, and psychosocial/ environmental determinants of health-related behaviors. Thus, they also define interventions to produce changes in knowledge, attitudes, motivations, self-confidence, skills, and social supports required for behavior change and maintenance [18].

These theories show that behavior is influenced by many factors and it is very difficult to predict. Pajares reports that the self-efficacy or selfefficacy perception contain the pleasant feeling to do assignments that link to motivation and doing tasks successfully in all men [19]. Also, in this present study the motivation, perception of personal ability and the effect on anticipation of a behavior is not considered. Also there was significant relation between age and mean score of preventive behaviors and duration of diabetes and mean score of preventive behaviors. Old people had the highest preventive behaviors. It is probable that there will be repetition of foot care behaviors while suffering from diabetes for a long-term. This finding doesn't confirm previous studies. Perrin et al. [8] reported that older people had problems in foot care behavior. They cited that older people are not precise enough in foot care because of their poor eyesight. Also they have difficulty in cutting fingernails. This finding is not similar to Wynn Nyunt study [20]. They cited that "older patients had better diabetes self-care behavior and a better self-efficacy level than younger patients". However, it was not confirmed in a study by Howteerakul et al. [21]. Furthermore the present study showed that people with longer diabetes had more preventive behaviors. It may be due to frequent education in hospital by nurses or pamphlet that is given to them. Also Membership date in the association should be noted which was not considered in our study. This finding was similar to the study of White et al. [22].
Also there was significant relationship between potentially damage behaviors and educational level. Patients with educations of primary level had more potentially damaging behaviors. It seems that people who are more educated have a better understanding of the consequences of failure to comply with a health behavior. Self-efficacy measures related to the ability to deal with a variety of stressful situations, measures of self-efficacy for self-care behaviors refer to beliefs about the ability to perform certain health behaviors. These behaviors may be defined broadly [23]. Patients at risk should understand the implications of the loss of protective sensation, the importance of foot monitoring on a daily basis, the proper care of the foot, including nail and skin care, and the selection of appropriate footwear $[24,25]$.

Inspite of establishing some institute the foot cares related problems are reported abundantly that is sometimes due to poor care and insufficient self-efficacy beliefs in amputated patients. We think that the present study inadequate training and bad following especially the low motivation in the senility period leads to poor foot care behavior. It is suggested that the interconnectivity of diabetic patients enhanced and encouragement by clinicians can be very useful. Bandura claim that people learn to have skills and capability to achieve success via encouraging directed by other people $[12,26]$. Despite of more sufficient research about the health belief models for altering the caring behavior as an effective standard, this model is not applicable in Iran and there is no training about the foot care to Iranian diabetic cases.

\section{Conclusion}

Regarding these results, foot care self-efficacy beliefs and self care behaviors do not have a strong relationship. It may be due to the low number of samples or sampling of only one center. In this study selfefficacy beliefs are directly related to health behavior, but it also affects health behaviors indirectly through its impact on patient's decision but we didn't assess it. Furthermore patients with diabetes, especially older diabetic patients and those with low education level should be advised to perform self care behavior and assessed for self-efficacy beliefs because they have many problems in self care.

\section{Acknowledgements}

The authors would like to thank the boss of Talaghani hospital and nurses in internal section and diabetes clinic. Also we would appreciate all of the patients participated in this study.

\section{References}

1. World Health Organization: Diabetes fact sheet (article online).

2. Diabetes Prevalence (article online).

3. Boulton AJ, Vileikyte L, Ragnarson-Tennvall G, Apelqvist J (2005) The global burden of diabetic foot disease. Lancet 366: 1719-1724.

4. Reiber G Epidemiology of foot Ulcers and amputations in the diabetic foot. In: Levin and O'Neals (Eds.). The diabetic foot (6thedn).

5. Payne CB (2000) Diabetes-related lower-limb amputations in Australia. Med J Aust 173: 352-354.

6. Gregg EW, Sorlie P, Paulose-Ram R, Gu Q, Eberhardt MS, et al. (2004) Prevalence of Lower-extremity disease in the US adult population $\geq 40$ years of age with and without diabetes: 1999-2000 national health and nutrition examination survey. Diabetes care 27: 1591-1597.

7. Vileikyte L, Gonzalez JS, Leventhal H, Peyrot MF, Rubin RR, et al. (2006) Patient Interpretation of Neuropathy (PIN) questionnaire: an instrument for assessment of cognitive and emotional factors associated with foot self-care. Diabetes Care 29: 2617-2624.

8. Perrin BM, Swerissen H, Payne C (2009) The association between foot-care self efficacy beliefs and actual foot-care behaviour in people with periphera neuropathy: a cross-sectional study. J Foot Ankle Res 2: 3. 
Citation: Hamedan MS, Hamedan MS, Torki ZS (2012) Relationship between Foot-Care Self-Efficacy Beliefs and Self Care Behaviors in Diabetic Patients in Iran (2011). J Diabetes Metab 3: 220. doi:10.4172/2155-6156.1000220

Page 5 of 5

9. Connor H, Mahdi OZ (2004) Repetitive ulceration in neuropathic patients. Diabetes Metab Res Rev 20: S23-S28.

10. Tomey A, Alligood M (2002) Nursing Theorists and their work. Mosby, St. Louis, Missouri, United States of America.

11. Lorig KR, Holman H (2003) Self-management education: history, definition, outcomes, and mechanisms. Ann Behav Med 26: 1-7.

12. Bandura A (1997) Self-Efficacy: The Exercise of Control. Worth publishers.

13. Diabetes (article online) How to choose foot wear.

14. Sloan HL (2002) Developing and testing of the foot care confidence scale. $J$ Nurs Meas 10: 207-218.

15. Sumalee Chuepan (2010) An Effect of Self-efficacy Enhancement on Foo Care Behaviors in Patients with Diabetes, type 2. Thai Journal of Nursing Council 25: 77-87.

16. Sarkar U, Fisher L, Schillinger D (2006) Is Self-Efficacy associated with diabetes self-management across race/ethnicity and health literacy? Diabetes Care 29: 823-829.

17. Benight CC, Bandura A (2004) Social cognitive theory of posttraumatic recovery: the role of perceived self-efficacy. Behav Res Ther 42: 1129-1148.

18. Elder JP, Ayala GX, Harris S (1999) Theories and intervention approaches to health-behavior change in primary care. Am J Prev Med 17: 275-284.
19. Pajares F (2005) Overview of Social Cognitive Theory and of Self-Efficacy.

20. Wynn Nyunt S, Howteerakul N, Suwannapong N, Rajatanun T (2010) SELFefficacy, self-care Behaviors and glycemic control among type-2 diabetes patients attending two private Clinics in Yangon, Myanmar. Southeast Asian J Trop Med Public Health 41: 943-951.

21. Howteerakul N, Suwannapong N, Rittichu C, Rawdaree P (2007) Adherence to regimens and glycemic control of patients with type 2 diabetes attending a tertiary hospital clinic. Asia Pac J Public Health 19: 43-49.

22. White JC, Bell RA, Langefeld CD, Jackson SA (2004) Preventive Foot-Care Practices Among Adults with Diabetes in North Carolina, 1997 to 2001. J Am Podiatr Med Assoc 94: 483-491.

23. Schwarzer R, Richert J, Kreausukon P, Remme L, Wiedemann AU, et al. (2010) Translating intentions into nutrition behaviors via planning requires selfefficacy: Evidence from Thailand and Germany. Int J Psychol 45: 260-268.

24. Perrin B, Swerissen H (2008) The Behavior and Psychological Functioning of People at High Risk of diabetes-related foot complications. Diabetes Educ 34 493-500.

25. Diabetes (article online). American Podiatric Medical Association (Journal of the American Podiatric Medical Association Volume 94 Number 5 483-491 2004

26. Boyd MA (2007) Psychiatric nursing: Contemporary practice. (4thedn) Lippincott Williams \& Wilkins, Philadelphia. 